see the unwisdom of their action and assist, rather than oppose, those who are fighting for the elevation of the standard of the profession which they are about to enter." This statement implies that the protest against the passage of the act has been made by a large number of medical students in the schools of Michigan, and such an implication is not only unjust, but is absolutely false. The students of the Department of Medicine and Surgery of the University of Michigan are not politicians and have never attempted in any way to influence legislation. They are otherwise engaged and have no time to send delegations to Lansing. Moreover, both the student body and the faculty of this school are in favor of the proposed amendment, and the graduates of this school are perfectly willing that their record before the examining boards of this country should be compared with the resords of any other medical school in the country. So far as I know the protest has come from only one medical school, and it is unfair for you to condemn the medical students in the schools of Michigan as a whole on account of the action taken by students from one school. When you make charges of the kind made in your editoriai you should be more specific and exact. Yours respectfully,

VICTOR C. VAUGIIAN.

[Dr. Vaughan evidently has not kept in touch with what is going on in his state or he would not say that "the protest has come from only one medical school." We have positive information as regards four, and indirect regarding the other. (There are five colleges in the state aside from the University of Michigan.) As a rule the senior students, as those graduating this year would probably be exempt, are taking no action; and the faculties are generally against the students' actions. We are glad to know that the students of the Department of Medicine and Surgery of the University of Michigan are not among those who are protesting.-EDIToR.]

\section{May We Not Secure Immunity from Fatal Chloroform Narcosis?}

INDIANAPoLis, March 19, 1903.

To the Editor:-Chloroform, pleasant to take, quickly producing thorough muscular relaxation and complete insensibility to pain, would be the ideal anesthetic were it not for the dangers attending its use. These dangers arise so quickly that the system is overwhelmed before the anesthetist realizes that death is impending. Fatalities occur, not necessarily when large amounts of chloroform are used, but when gasps and deep inspirations fill the innermost alveoli with the concentrated vapor. Various apparatuses have been devised to properiy dilute the vapor, but none has been altogether satisfactory.

Parturient and pregnant women seldom, if ever, succumb to chloroform narcosis, for the following reasons:

1. In the parturient the central nervous system is in a state of congestion.

2. In both the pregnant and the parturient movement of the diaphragm is greatly restricted becanse of abdominal distension; therefore, breathing is necessarily shallow. As a consequence, chloroform would have to be given in very concentrated vapor, indeed, to prove dangerous to the patient, for it must be greatly diluted by admixtures with the residual air of the lungs previous to absorption and, in such cases, the shallow respiration would make it practically impossible to overwhelm the patient with an overdose in a few respirations.

In view of these facts, would it not be wise before the administration of chloroform to artificially restrict the movements of the diaphragm? An abdominal bandage, preferably an elastic bandage, would assure shallow breathing, and it would appear, secure at least the immunity from "drowning" in chloroform which belongs to the pregnant and the parturient.

H. W. DudLey, M.D.

\section{Eye-Strain and the General Practitioner.}

Chicago, March 23, 1903.

To the liditor:-Referring to your review in THE Jourval of March 14 of Dr. Gould's book, "Biographic Clinies," dealing with the question of eye-strain anl its eTests, I can not but think it unfortunate that you should alopt sach a critical attitude, because the general impression left in the mind of the reader will be that oculists are very prone to exaggerate the importance of eye-strain, and that in the absence of very direct indications the counsel of an oculist will be deemed superfluous and be dispensed with.

It may be that Dr. Gould's claims are excessive, but as a general practitioner I do most certainly know that not nearly enough of our patients are referred to the oculist. Provided that a conscientious and skilled refractionist be employed, the fee and time spent in the examination are the only losses to the patient, yet many patients who could well afford these if it were only to exclude the possible culpability of the eye, are allowed to suffer needless tortures for years because of the ignorance or thoughtlessness of the general practitioner, or sometimes his jealousy of the specialist.

As a general practitioner I have seen so much relief afforded patients by the wearing of properly-fitted glasses, and in such very unexpected ways, that I feel very keenly on this subject, and for this reason am inclined to resent anything that tends to relieve the physician of his responsibility to his patient or encourages him to undervalue the exceeding importance of eyestrain in causing disturbances anatomically remote from the eye and very various in kind. The judicious employment of the services of an expert refractionist-and competency of the highest order is a sine qua non in refraction work-will rob the practitioner of many of his chronic cases, and in place of fees he will have to be content with gratitude-if the oculist does not get all of that. Our duty, however, is none the less clear. Very truly yours, James W. WALKER, MD.

\section{Newspaper Reputation. \\ Chicago, March 24, 1903.}

In view of the surprising and, to some of us, painful newspaper publicity that characterized the now famous visit of Professor Lorenz to this country, the following elippings from the daily papers are of interest:

"DR. MUELI.ER PERFORMS FOUR OPERATIONS.

Dr. Frederick Mueller, the pupil of Dr. Lorenz, performed four of the most difficult operations for congenital dislocation of the hip in Beth Israel Hospital to-day," etc., etc.-New York Letter, the Chicago Tribune, March 15, 1903.

"LORENZ MaCHINe is USED SUCCESSFULly.

For the first time in this country the Lorenz machine has been used in an operation for hip disease. The operation was performed by Dr. Frederick Mueller, a pupil of Dr. Lorenz," etc., etc., etc. New York Letter, Chicago Record-Herald, March 17, 1903.

"Dr. MUELler is Back. Associate of Dr. LORENZ Will Practice ORTHOPEDIC SURGERY HERE.

TO REMAIN PERMANENTLY.

CoTRd VIENNa SURGeon WILL BECOME A CITIZEN AS SOON AS LATS PERMIT,"

-Chicago Record-Herald, March 23, 1903.

And then follows a third of a column, including what purports to be an interview with Dr. Mueller, the substance of which is that he likes this country so much that he couldn't stay away; that "There is a great field here for orthopedic surgery. Chicago is centrally located, and people will flock here for treatment from all over the country."

These are but samples taken from the public press. Each of them contains what purports to be some interview with Dr. Mueller.

How long will it be before it is learned that such newspaper attentions, however profitable from a business standpoint, are not accepted by medical gentlemen in this country?

W. A. Puser.

\section{Marriages.}

Deyo L. Ramsdelt, M.D., Lincoln, Neb., to Miss Gertrude Musser of Orangeville, IIl, March 9.

Samuer. Cratg Plemmer, M.D., Chicago, to Miss Mary Louisa Middleton, daughter of the late Dr. W. D. Middleton of Davenport, Iowa, Mareh 18.

Carlton Lee Starkweatier, M.D., Occoquan, Va., to Miss Jennie Atkinson Jones, daughter of the late Elias Jones, M.D., of Fairfax Courthouse, Va., at Trinity Church, Washington, D. C., March 12. 